In conclusion, we have shown that in adult asthmatics who have a preserved FEV1, the presence of persistent small airway dysfunction was associated with poorer control, perhaps suggesting the presence of a defined small airway asthma phenotype.

0 @ERSpublications

In asthmatics with preserved FEV1, small airway dysfunction was associated with poorer long-term control http://ow.ly/yAWgY

Arvind Manoharan, William J. Anderson, Joseph Lipworth, Ibrahim Ibrahim and Brian J. Lipworth

Scottish Centre for Respiratory Research, Ninewells Hospital and Medical School, University of Dundee, Dundee, UK.

Correspondence: Brian J. Lipworth, Scottish Centre for Respiratory Research, Division of Cardiovascular and Diabetes Medicine, Medical Research Institute, University of Dundee, Ninewells Hospital and Medical School, Dundee DD1 9SY, UK. E-mail: b.j.lipworth@dundee.ac.uk

Received: April 112014 | Accepted after revision: June 152014 | First published online: July 172014

Conflict of interest: Disclosures can be found alongside the online version of this article at erj.ersjournals.com

\title{
References
}

1 Lipworth B. Targeting the small airways asthma phenotype: if we can reach it, should we treat it? Ann Allergy Asthma Immunol 2013; 110: 233-239.

2 Bateman ED, Boushey HA, Bousquet J, et al. Can guideline-defined asthma control be achieved? The Gaining Optimal Asthma ControL study. Am J Respir Crit Care Med 2004; 170: 836-844.

3 Anderson WJ, Zajda E, Lipworth BJ. Are we overlooking persistent small airways dysfunction in communitymanaged asthma? Ann Allergy Asthma Immunol 2012; 109: 185-189.

4 Miller MR, Hankinson J, Brusasco V, et al. Standardisation of spirometry. Eur Respir J 2005; 26: 319-338.

5 Shi Y, Aledia AS, Tatavoosian AV, et al. Relating small airways to asthma control by using impulse oscillometry in children. J Allergy Clin Immunol 2012; 129: 671-678.

6 Shi Y, Aledia AS, Galant SP, et al. Peripheral airway impairment measured by oscillometry predicts loss of asthma control in children. J Allergy Clin Immunol 2013; 131: 718-29.

7 Rao DR, Gaffin JM, Baxi SN, et al. The utility of forced expiratory flow between $25 \%$ and $75 \%$ of vital capacity in predicting childhood asthma morbidity and severity. J Asthma 2012; 49: 586-592.

8 Busse WW, Brazinsky S, Jacobson K, et al. Efficacy response of inhaled beclomethasone dipropionate in asthma is proportional to dose and is improved by formulation with a new propellant. J Allergy Clin Immunol 1999; 104: $1215-1222$.

9 Goldin JG, Tashkin DP, Kleerup EC, et al. Comparative effects of hydrofluoroalkane and chlorofluorocarbon beclomethasone dipropionate inhalation on small airways: assessment with functional helical thin-section computed tomography. J Allergy Clin Immunol 1999; 104: S258-S267.

10 Nicolini G, Chetta A, Simonazzi A, et al. Both bronchial and alveolar exhaled nitric oxide are reduced with extrafine beclomethasone dipropionate in asthma. Allergy Asthma Proc 2010; 31: 85-90.

11 Cohen J, Postma DS, Douma WR, et al. Particle size matters: diagnostics and treatment of small airways involvement in asthma. Eur Respir J 2011; 37: 532-540.

12 Juniper EF, Price DB, Stampone PA, et al. Clinically important improvements in asthma-specific quality of life, but no difference in conventional clinical indexes in patients changed from conventional beclomethasone dipropionate to approximately half the dose of extrafine beclomethasone dipropionate. Chest 2002; 121: 1824-1832.

13 Price D, Martin RJ, Barnes N, et al. Prescribing practices and asthma control with hydrofluoroalkanebeclomethasone and fluticasone: a real-world observational study. J Allergy Clin Immunol 2010; 126: 511-518.

14 Barnes N, Price D, Colice G, et al. Asthma control with extrafine-particle hydrofluoroalkane-beclometasone vs. large-particle chlorofluorocarbon-beclometasone: a real-world observational study. Clin Exp Allergy 2011; 41: $1521-1532$.

15 Colice G, Martin RJ, Israel E, et al. Asthma outcomes and costs of therapy with extrafine beclomethasone and fluticasone. J Allergy Clin Immunol 2013; 132: 45-54.

\section{Reduced lung function and the risk of out-of-hospital sudden cardiac death}

\author{
To the Editor:
}

Although some previous studies have shown that reduced lung function is related to cardiovascular mortality little is known about the relationship between lung function tests and the risk of sudden cardiac death (SCD) among the general population [1-5]. This prospective population-based study was designed to 
determine if impaired lung function (forced expiratory volume in $1 \mathrm{~s}(\mathrm{FEV} 1)$ ) is a risk factor for out-ofhospital SCD in the general male population.

The study population was a representative sample of males living in the city of Kuopio, Finland and its surrounding rural communities, who were 49-67 years of age at baseline examinations performed between 1991 and 1993. The study was approved by the Research Ethics Committee of the University of Kuopio (Kuopio, Finland) and each participant gave written informed consent. The study reported here is based on data obtained from 1441 participants who had data from lung function test measurements and did not have chronic obstructive pulmonary disease (COPD), asthma or lung cancer at baseline. The current analysis was based males with complete spirometry data, whereas the whole population is described elsewhere [6]. During the 20-year follow-up period, a total 68 out-of-hospital SCDs occurred. Lung function was measured by FEV1 using standard spirometry at baseline. There were no losses to follow-up.

A death was determined SCD when it occurred either within $1 \mathrm{~h}$ after the onset of an abrupt change in symptoms or within $24 \mathrm{~h}$ after onset of symptoms when clinical findings did not reveal a noncardiac cause of sudden death [6]. Risk factors for out-of-hospital SCD were analysed using Cox multivariate models. Cox models were adjusted for age and other demographic and clinical factors previously reported to be predictive of SCD by considering their clinical relevance. The multivariate model was further adjusted for smoking, alcohol consumption, systolic blood pressure, body mass index, serum low-density lipoprotein (LDL) and high-density lipoprotein (HDL) cholesterol, prevalent myocardial infarction, type 2 diabetes, and C-reactive protein, The analysis were repeated among smokers $(n=401)$ and nonsmokers $(n=849)$ separately. Relative risks with $95 \%$ confidence intervals, adjusted for clinical risk factors, were estimated as antilogarithms of the coefficients from multivariable models. Analyses were also performed on a model including males with lung diseases.

The mean value for FEV1 was $96.6 \%$ predicted (range: $15.4-226.7 \%$ pred). Males who died due to SCD were older, had higher systolic and diastolic blood pressure, had higher serum levels of HDL cholesterol and triglycerides, were more likely to have prevalent coronary heart disease, previous myocardial infarction, hypertension and diabetes, and smoked more as compared with those who did not die due to SCD. Among 849 nonsmokers there were 36 SCD cases, whereas among 401 smokers 32 cases of SCD occurred. After adjusting for age, low FEV1 (lowest quintile: $<71.8 \%$ pred) was associated with a 5.6 -fold increased risk of SCD $(95 \%$ CI $2.32-13.71 ; \mathrm{p}<0.001)$ as compared to the highest quintile of FEV1 ( $\geqslant 118.9 \%$ pred). After further adjustment for established risk factors, the risk was a 3.5-fold increased risk for SCD among males in the lowest quintile. After additional adjustment for maximal oxygen uptake the relative risk for SCD was 2.90 (95\% CI 1.16-7.23; $\mathrm{p}=0.02$ ). When further adjusted for smoking status (current, former or never), in addition to pack-years, the results remained statistically significant (relative risk 3.3, 95\% CI 1.33-8.07; $\mathrm{p}=0.009$ ). We found that the C-index for discrimination changed from 0.794 (95\% CI $0.739-0.846$ ) to 0.815 (95\% CI 0.783-0.844) after adding FEV1 into the model, and integrated discrimination improvement was 0.018 (95\% CI $0.005-0.030 ; \mathrm{p}=0.005)$.

This prospective study shows that FEV1 is associated with an increased risk of out-of-hospital SCD in the general population. The current study demonstrates that lung function tests provided prognostic value beyond that predicted by common cardiovascular risk factors among males with no history of COPD, asthma and lung cancer. Our findings indicate that airflow obstruction is an important risk factor for SCD in smokers (relative risk 5.7, 95\% CI 1.17-27.56; $\mathrm{p}=0.031$ ). Although systemic inflammation probably contributes to the association between the impairment of lung function and cardiovascular diseases (CVDs), factors including the capture and elimination of external toxic agents may also play a role in the prevention of CVDs [7]. It has been shown that C-reactive protein upregulates the production of proinflammatory cytokines and tissue factors by monocytes and increases the uptake of LDL by macrophages, interacting with other inflammatory mediators to create foam cells that in turn serve as building blocks for vulnerable atherosclerotic plaques $[8,9]$. However, in this study, the association between FEV 1 and SCD remained significant, although the level of C-reactive protein was taken into account. Poor lung function with bronchial wall oedema can lead to airway obstruction inducing myocardial ischaemia [10, 11]. It has also been suggested that the increased risk may be associated with alcohol intake, which has been shown to influence lung function leading to SCD [12]. However, our main findings were independent of alcohol intake. A limitation of this study may be residual confounding due to unmeasured variables [5]. Another limitation of study was that we included only middle-aged males. Finally, we have no data on changes in health habits and medication during the follow-up period, which is well known issue in epidemiological studies.

These findings emphasise the importance of FEV1 as potentially useful in risk stratification for out-ofhospital SCD in the general population, although further studies are needed. 

males http://ow.ly/A0SjL

Sudhir Kurl ${ }^{1}$, Sae Young Jae ${ }^{2}$ and Jari A. Laukkanen ${ }^{1,3}$

${ }^{1}$ Institute of Public Health and Clinical Nutrition, School of Public Health and Clinical Nutrition, University of Eastern Finland, Kuopio, Finland. ${ }^{2}$ Dept of Sports Informatics, College of Arts and Physical Education, University of Seoul, South Korea. ${ }^{3}$ Dept of Internal Medicine, Lapland Central Hospital, Rovaniemi, Finland.

Correspondence: Sudhir Kurl, Institute of Public Health and Clinical Nutrition, Dept of Medicine, University of Eastern Finland, P.O. Box 1627, 70211 Kuopio, Kuopio, Finland. E-mail: Sudhir.kurl@uef.fi

Received: March 202014 | Accepted after revision: July 242014 | First published online: Aug 192014

Conflict of interest: None declared.

\title{
References
}

1 Friedman GD, Klatsky AL, Siegelaub AB. Lung function and risk of myocardial infarction and sudden cardiac death. N Engl J Med 1976; 294: 1071-1075.

2 Engström G, Lind P, Hedblad B, et al. Lung function and cardiovascular risk: relationship with inflammationsensitive plasma proteins. Circulation 2002; 106: 2555-2560.

3 Schünemann HJ, Dorn J, Grant BJ, et al. Pulmonary function is a long-term predictor of mortality in the general population: 29-year follow-up of the Buffalo Health Study. Chest 2000; 118: 656-664.

4 Bang KM, Gergen PJ, Kramer R, et al. The effect of pulmonary impairment on all-cause mortality in a national cohort. Chest 1993; 103: 536-540.

5 Sin DD, Wu L, Man SFP. The relationship between reduced lung function and cardiovascular mortality: a population-based study and a systematic review of the literature. Chest 2005; 127: 1952-1959.

6 Laukkanen JA, Mäkikallio TH, Rauramaa R, et al. Cardiorespiratory fitness is related to the risk of sudden cardiac death: a population-based follow-up study. J Am Coll Cardiol 2010; 56: 1476-1483.

7 Sparrow D, Weiss ST, Vokonas PS, et al. Forced vital capacity and the risk of hypertension. The Normative Aging Study. Am J Epidemiol 1988; 127: 734-741.

8 Pasceri V, Willerson JT, Yeh ET. Direct proinflammatory effect of C-reactive protein on human endothelial cells. Circulation 2000; 102: 2165-2168.

9 Zwaka TP, Hombach V, Torzewski J. C-reactive protein-mediated low density lipoprotein uptake by macrophages: implications for atherosclerosis. Circulation 2001; 103: 1194-1197.

10 Kannel WB, Wolf PA, Verter J. Manifestations of coronary disease predisposing to stroke. The Framingham study. JAMA 1983; 250: 2942-2946.

11 Cabanes LR, Weber SN, Matran R, et al. Bronchial hyperresponsiveness to methacholine in patients with impaired left ventricular function. N Engl J Med 1989; 320: 1317-1322.

12 Lange P, Groth S, Mortensen J, et al. Pulmonary function is influenced by heavy alcohol consumption. Am Rev Respir Dis 1988; 137: 1119-1123.

\section{Autonomic dysregulation: a mechanism of asthma death}

\author{
To the Editor:
}

Therapeutic advances in the management of asthma have led to a gradual but sustained reduction in mortality $[1,2]$. However, the death of otherwise healthy young individuals remains a tragic and all too frequent occurrence. The unheralded demise of two of our patients with previously minimally troublesome asthma led us to reconsider the mode of death in such patients. Numerous studies and retrospective reports have attributed such mortality to preventable factors such as inadequate severity assessment, discontinuity of medical care, poor concordance to prescribed therapies and poor management of acute asthma exacerbations [3,4]; others have attributed fatalities to significant behavioural, socioeconomic or psychosocial factors including smoking, denial, depression and alcohol abuse $[1,5,6]$.

Whilst these associations are undeniably important they do not adequately explain the observed clinical picture of precipitous deterioration, loss of consciousness, and death. RoBIN et al. [7] reported two patients with an abrupt demise, one during a telephone conversation and with no prior asthma-related symptoms. Grubb et al. [8] followed a teenage boy with a history of long-standing asthma after repeated near fatal asthma episodes requiring resuscitation. Our similar experience of two unexpected fatalities caused us to 